\author{
Ming Der Chen ${ }^{1,2 *}$ and Yuh Min Song ${ }^{2}$ \\ ${ }^{1}$ General Education Center, Overseas Chinese \\ University, Taichung, Taiwan \\ ${ }^{2}$ Division of Endocrinology and Metabolism, \\ Taichung Veterans General Hospital, Taichung, \\ Taiwan \\ Dates: Received: 17 November, 2016; Accepted: \\ 28 November, 2016; Published: 29 November, 2016 \\ ${ }^{*}$ Corresponding author: Dr. Ming-Der \\ Chen, General Education Center, Overseas \\ Chinese University, No.100 Chiao- \\ Kwang Road, Taichung 40721, Taiwan, \\ Tel: +886-4-27016855; Ext: 2182; E-mail: \\ mdchen@ocu.edu.tw; mdchen1104@gmail.com \\ www.peertechz.com \\ Keywords: Branched-chain amino acids; Glutamine; \\ Obesity; Ornithine; Taurine
}

\author{
Short Communication
}

\section{The Relationship between Plasma Levels of Large Neutral Amino Acids and Leptin in Women with or Without Obesity}

\section{Introduction}

Obesity, characterized as excessive fat accumulation, is caused by interactions of genetic, environmental, and lifestyle factors [1]. Obesity increases the risk of various diseases including type 2 diabetes mellitus. Insulin resistance, commonly occurring in obese subjects, is attributed to the defects in insulin action on mediating the metabolism of macronutrients in target tissues [2]. Insulin increases amino acids uptake and protein biosynthesis in a tissue-specific manner [3]. In turn, certain amino acids can mediate insulin secretion [4].

Branched-chain (BCAA=valine+leucine+ isoleucine) and aromatic (AAA=tyrosine+phenylalanine+tryptophan) amino acids are of particular interest because they have distinctive effects to against obesity formation, as in regulating glucose oxidation [5] and satiety factors secretion [6,7]. Paradoxically, obese subjects have hyperaminoacidemia [8]. A close link between elevated plasma BCAA and obesity-related diabetes has also been found [9]. Elevated plasma BCAA may inhibit insulin signaling and contribute to insulin resistance [10]. Moreover, obese subjects have depressed activity in BCAA catabolism [11]. Leptin, produced by adipocytes, is secreted in proportion to the amount of body fat mass [12]. Besides regulating energy metabolism, leptin also positively affects amino acids uptake [13]. Since the changes in fasting plasma BCAA profile among ob/ob mouse (leptin deficiency), fa/fa rat (leptin receptor deficiency), and high-fat obese rodents (leptin resistance) are inconsistent [11,14,15], an interaction between leptin and amino acids in blood was thus proposed.

\section{Methods}

A cross-sectional study was designed to assess the relationship between leptinemia and aminoacidemia. This study was approved by the Research Ethics Committee of the Overseas Chinese University (Ocit92A097). By using a online software "Raosoft Sample Size Calculator", a sample size of 40 was selected to ensure a desired analysis power of 0.9 for 2 -sides tests at $\alpha=0.05$. Forty women with obesity (BMI $=30.8 \pm 3.5 \mathrm{~kg} / \mathrm{m} 2$, age $=25.1 \pm 4.3 \mathrm{yr}$ ) and their agematched controls $(\mathrm{BMI}=20.7 \pm 1.8 \mathrm{~kg} / \mathrm{m} 2$, age $=25.6 \pm 5.8 \mathrm{yr})$ were recruited from university staff and students during their annual physical check-up. All participants had no diabetes mellitus or cardiovascular disorders. Subjects who were taking any drug or nutritional supplement, or who were on a special diet were excluded. After obtaining signed consents, overnight fasting blood sample of each participant was collected. A 3-day food record was also obtained to exclude the possibility of there being any significant differences in diet. Glucose, insulin, and leptin were measured as described elsewhere [12]. Amino acids were assessed by the High Performance Amino Acid Analyzer (Beckman Model 7300, Beckman Coulter Inc., Atlanta, GA, USA) following the manufacturer's instructions [16]. Because plasma large neutral amino acids (LNAA=BCAA+AAA) determine the bioavailability of some amino acids like tryptophan, the ratio of Leu/LNAA was also determined. Statistical analyses were conducted by ANOVA and unpaired Student's $t$-test. The difference was considered to be significant when $P$ value was $<0.05$. Measured parameters, unless specifically indicated, which reached the statistical significance were presented in Tables.

\section{Results}

As expected, obese women had higher insulin, leptin and HOMA-IR (homeostasis model assessment-insulin resistance), whereas similar glucose levels compared to normal controls (Table 1). Furthermore, obese women had significant elevation in LNAA, ornithine and taurine, but reduction in glutamine. When all data were pooled, there was a significant correlation between LNAA and leptin, HOMA-IR, Leu/LNAA, respectively (Table 2). Leptin also correlated with HOMA-IR and Leu/LNAA.

\section{Discussion}

Leptin is an adipocyte-derived protein and closely related to the amount of body fat mass [12]. It is well known that visceral fat secrets less leptin into circulation than subcutaneous fat dose [13]. These facts 
Table 1: Determined plasma variables in women with or without obesity

\begin{tabular}{|c|c|c|}
\hline & Normal $(n=40)$ & Obese $(n=40)$ \\
\hline Glucose (mg/dL) & $86 \pm 13$ & $91 \pm 15^{\mathrm{ns}}$ \\
\hline Insulin $(\mu \mathrm{U} / \mathrm{mL})$ & $5.8 \pm 3.2$ & $15.2 \pm 7.2^{*}$ \\
\hline HOMA-IR & $1.2 \pm 0.7$ & $4.2 \pm 2.4$ * \\
\hline Leptin (ng/mL) & $6.7 \pm 2.9$ & $17.8 \pm 5.3 *$ \\
\hline Leucine $(\mu \mathrm{mol} / \mathrm{L})$ & $120 \pm 9$ & $161 \pm 12$ * \\
\hline Isoleucine $(\mu \mathrm{mol} / \mathrm{L})$ & $84 \pm 25$ & $95 \pm 18$ * \\
\hline Valine $(\mu \mathrm{mol} / \mathrm{L})$ & $169 \pm 23$ & $295 \pm 16$ * \\
\hline Phenylalanine $(\mu \mathrm{mol} / \mathrm{L})$ & $58 \pm 10$ & $85 \pm 15$ * \\
\hline Tryptophan $(\mu \mathrm{mol} / \mathrm{L})$ & $63 \pm 5$ & $84 \pm 7$ * \\
\hline Tyrosine $(\mu \mathrm{mol} / \mathrm{L})$ & $66 \pm 20$ & $76 \pm 15^{*}$ \\
\hline Glutamine $(\mu \mathrm{mol} / \mathrm{L})$ & $118 \pm 21$ & $74 \pm 13$ * \\
\hline Ornithine $(\mu \mathrm{mol} / \mathrm{L})$ & $63 \pm 13$ & $126 \pm 38$ * \\
\hline Taurine $(\mu \mathrm{mol} / \mathrm{L})$ & $48 \pm 14$ & $81 \pm 22$ * \\
\hline LNAA $(\mu \mathrm{mol} / \mathrm{L})$ & $560 \pm 87$ & $796 \pm 43$ * \\
\hline Leu/LNAA & $0.29 \pm 0.04$ & $0.25 \pm 0.02$ * \\
\hline
\end{tabular}

Mean \pm SD. ns: non-significance. * $P<0.05$

HOMA-IR $=[($ fasting glucose $\mathrm{mg} / \mathrm{dL} \div 18) \times($ fasting insulin $\mu \mathrm{U} / \mathrm{mL})] \div 22.5$.

LNAA=Large neutral amino acids, including leucine, isoleucine, valine, tyrosine, phenylalanine, and tryptophan.

Table 2: Significant correlation ( $r$ value, $P<0.05)$ between measured parameters

\begin{tabular}{|l|c|c|c|}
\hline & Leptin & HOMA-IR & Leu/LNAA \\
\hline LNAA & 0.752 & 0.608 & -0.720 \\
\hline Leptin & & 0.431 & -0.415 \\
\hline HOMA-IR & & & -0.305 \\
\hline
\end{tabular}

also explain the discrepancy in leptinemia between males and females. Though this study was limited by only conducting in women to the evaluation of the relationship between leptinemia and aminoacidemia in obesity, some new evidence is presented. Obesity-related hyperaminoacidemia has long been interpreted as a consequence of insulin resistance $[8,9,13]$. However, hyperaminoacidemia can simply occur because obese subjects commonly eat more. Our obese women exhibited moderate insulin resistance (HOMA-IR $<5$ ), thus, the elevation of plasma LNAA might be mainly due to increased food consumption. Furthermore, obese subjects usually have reduced lean mass, and most of the increment in body weight is from fat accumulation [1]. Because amino acids metabolism mainly occurs in lean mass, large body fat deposit should affect the partitioning of plasma amino acids. Indeed, BCAA catabolism is reduced in obese subjects, which leads to the elevation of plasma BCAA levels [11]. Although we did not measure the change in BACC metabolism because of the limitation in obtaining tissue samples, our data of a positive correlation between LNAA and leptin supported this assumption.

Ob/ob mice, but not fa/fa rats, have higher plasma BCAA levels than lean controls [11]. Because leptin can increase amino acids uptake [12], this discrepancy may be caused by whether leptin is functionally produced. However, LNAA and leptin were significantly elevated in our obese women. Interestingly, a recent report showed leptin inhibits intestinal absorption of amino acids [17]. Further investigation on identifying the real action of leptin (systematic or local) on amino acids uptake in intestinal or adipose tissues is warranted. Since leucine contributes to about $40 \%$ of plasma leptin [7], lower Leu/LNAA in our obese women and its inversed relation with leptinemia might reflect more leucine has been taken into adipocytes to synthesize leptin. Whether lower Leu/LNAA also can denote an effective insulin-dependent increase in leucine uptake or that leptin can prompt leucine influx into adipocytes in our obese women needs to be elucidated.

Glutamine is derived from 2-oxoglutarate in the TCA cycle [18]. Lower plasma glutamine in obese women might result from reduced BCAA uptake into tissues, leading to less 2-oxoglutarate availability $[18,19]$. Ornithine, an intermediate of urea cycle, was elevated in obese women suggesting that they might have abnormal hepatic urea synthesis $[11,18]$. Taurine supplementation to obese subjects can effectively increase fatty acid oxidation [20]. Furthermore, high-fat obese rodents have high hepatic taurine content with accompanying hypotaurinemia $[18,20]$. Thus, elevated hepatic taurine is a compensatory mechanism to overcome high-fat supply. As in a previous animal study [15], our obese women also had hypertaurinemia. However, whether this finding is attributed to insulin resistance-induced reduction in taurine uptake into target tissues remains unclear.

Our data revealed obese women had significant alterations in plasma levels of various amino acids, including LNAA. Hyperinsulinemia and hyperleptinemia, caused by the increase in food consumption and body fat accumulation, contributed to the alteration in plasma amino acids profile in these subjects. Furthermore, long-term elevation of plasma LNAA could aggravate insulin resistance and lead to the development of type 2 diabetes. Thus, our results might be practical for those who receive obesity therapy to include a diet-exercise program to increase their lean mass. It is also recommended that clinicians should periodically monitor these described factors to avoid the risks associated with insulin resistance. Nevertheless, these suggestions remain to be elucidated by further studies of larger study groups containing both genders.

\section{Acknowledgements}

We thank Dr. Pi-Yao Lin (Department of Chemistry, Tunghai University) for providing laboratory facilities, and Ho-Chi Han, WeiChen Liao, Shy-Jane Liou for technical assistance.

\section{References}

1. Gesta S, Tseng YH, Kahn CR (2007) Developmental origin of fat: tracking obesity to its source. Cell 131: 242-256.

2. Rattarasarn C (2006) Physiological and pathophysiological regulation of regional adipose tissue in the development of insulin resistance and type 2 diabetes. Acta Physiol 186: 87-101.

3. Boirie Y, Short KR, Ahlman B, Charlton M, Nair KS (2001) Tissue-specific regulation of mitochondrial and cytoplasmic protein synthesis rates by insulin. Diabetes 50: 2652-2658.

4. Dixon G, Nolan J, McClenaghan N, Flatt PR, Newsholme P (2003) A comparative study of amino acid consumption by rat islet cells and the clonal beta-cell line BRIN-BD11 - the functional significance of L-alanine. J Endocrinol 179: 447-454. 
5. Doi M, Yamaoka I, Nakayama M, Sugahara K, Yoshizawa F (2007) Hypoglycemic effect of isoleucine involves increased muscle glucose uptake and whole body glucose oxidation and decreased hepatic gluconeogenesis. Am J Physiol Endocrinol Metab 292: E1683-1693.

6. Wurtman RJ, Wurtman JJ (1996) Brain serotonin, carbohydrate-craving obesity and depression. Adv Exp Med Biol 398: 35-41.

7. Lynch CJ, Gern B, Lloyd C, Hutson SM, Eicher R, et al. (2006) Leucine in food mediates some of the postprandial rise in plasma leptin concentrations. Am J Physiol Endocrinol Metab 291: E621-630.

8. Newgard CB, An J, Bain JR, Muehlbauer MJ, Stevens RD, et al. (2009) A branched-chain amino acid-related metabolic signature that differentiates obese and lean humans and contributes to insulin resistance. Cell Metab 9 : 311-326

9. Wang TJ, Larson MG, Vasan RS, Cheng S, Rhee EP, et al. (2011) Metabolite profiles and the risk of developing diabetes. Nat Med 17: 448-453.

10. Tremblay F, Marette A (2001) Amino acid and insulin signaling via the mTOR/ p70 S6 kinase pathway. A negative feedback mechanism leading to insulin resistance in skeletal muscle cells. J Biol Chem 276: 38052-38060.

11. She P, Van Horn C, Reid T, Hutson SM, Cooney RN, et al. (2007) Obesity related elevations in plasma leucine are associated with alterations in enzymes involved in branched-chain amino acid metabolism. Am J Physiol Endocrinol Metab 293: E1552-E1563.

12. Chen MD, Song YM, Lin PY (2000) Zinc may be a mediator of leptin production in humans. Life Sci 66: 2143-2149.
13. Cammisotto PG, Levy E, Bukowiecki L, Bendayan M (2010) Cross-talk between adipose and gastric leptins for the control of food intake and energy metabolism. Prog Histochem Cytochem 45: 143-200.

14. Wijekoon EP, Skinner C, Brosnan ME, Brosnan JT (2004) Amino acid metabolism in the Zucker diabetic fatty rat: effects of insulin resistance and of type 2 diabetes. Can J Physiol Pharmacol 82: 506-514.

15. Duggan GE, Hittel DS, Sensen CW, Weljie AM, Vogel HJ, et al. (2011) Metabolomic response to exercise training in lean and diet-induced obese mice. J Appl Physiol 110: 1311-1318.

16. Lepage N, McDonald N, Dallaire L, Lambert M (1997) Age-related distribution of plasma amino acid concentrations in a healthy pediatric population. Clin Chem 43: 2397-2402

17. Fanjul C, Barrenetxe J, De Pablo-Maiso L, Lostao MP (2015) In vivo regulation of intestinal absorption of amino acids by leptin. $\mathrm{J}$ Endocrinol 224 : 17-23.

18. Xie B, Waters MJ, Schirra HJ (2012) Investigating potential mechanisms of obesity by metabolomics. J Biomed Biotech 2012: 805683.

19. Waldram A, Holmes E, Wang Y, Rantalainen M, Wilson ID, et al. (2009) Topdown systems biology modeling of host metabotype-microbiome association in obese rodents. J Proteome Res 8: 2361-2375.

20. Tsuboyama-Kasaoka N, Shozawa C, Sano K, Kamei Y, Kasaoka S, et al. (2006) Taurine (2-aminoethanesulfonic acid) deficiency creates a vicious circle promoting obesity. Endocrinology 147: 3276-3284.

Copyright: (c) 2016 Chen MD, et al. This is an open-access article distributed under the terms of the Creative Commons Attribution License, which permits unrestricted use, distribution, and reproduction in any medium, provided the original author and source are credited. 